\title{
Diagnostic Radioimmunoassay for Familial Amyloidotic Polyneuropathy Before Clinical Onset
}

\author{
Masamitsu Nakazato, Teruyuki Kurihara, Shigeru Matsukura, Kenji Kangawa*, and Hisayuki Matsuo* \\ Departments of Medicine and *Biochemistry, Miyazaki Medical College, Kiyotake, Miyazaki 889-16, Japan
}

\begin{abstract}
The purpose of this study is to develop an early diagnostic method for familial amyloidotic polyneuropathy (FAP) before clinical manifestations appear around the age of $30 \mathrm{yr}$. Amyloid fibrils isolated from type I FAP (FAP') of Portuguese, Swedish, and Japanese origins consist of a variant transthyretin (TTR) that contains a methionine-for-valine substitution at position 30 or a mixture of normal TTR and this variant form. The variant TTR is present in the serum of FAP ${ }^{1}$ patients and can be measured by a radioimmunoassay (RIA) based on a nonapeptide (positions 22-30) derived from the variant TTR. Serum levels of the variant TTR in 45 Japanese FAP ${ }^{1}$ patients range from 4.71 to 17.61 $\mathrm{mg} / \mathrm{dl}$ with a mean value of $9.18 \mathrm{mg} / \mathrm{dl}$. The variant TTR is not present in the serum of $\mathbf{1 0 0}$ normal individuals, in four cases of primary and six cases of secondary amyloidosis, nor in 26 noninheriting members of families with FAP'. The variant TTR level is measured in 24 children of 15 FAP $^{1}$ patients as well. The variant TTR is already present in nine symptom-free children with the mean serum level of $11.90 \mathrm{mg} / \mathrm{dl}$, but it is not present in 15 other children. FAP ${ }^{1}$ patients can be differentiated from non-FAP by this noninvasive diagnostic method even within families. The RIA can be applied worldwide to this intractable disorder for early diagnosis during childhood and for appropriate genetic counseling.
\end{abstract}

\section{Introduction}

Family trees carrying FAP have been reported from various countries including Portugal, Israel, Finland, Germany, Sweden, Brazil, U. S. A., and Japan (1). Type I FAP (FAP $)^{1}$ of Japanese origin is characterized by dissociated sensory disturbance and autonomic dysfunction in the early course, followed by motor

Address correspondence and reprint requests to Dr. Nakazato, The Third Department of Internal Medicine, Miyazaki Medical College, $5200 \mathrm{Ki}$ hara, Kiyotake, Miyazaki 889-16, Japan.

Received for publication 28 October 1985 and in revised form 28 January 1986.

1. Abbreviations used in this paper: $\mathrm{AF}_{\mathrm{J}}$, amyloid fibril protein from Japanese patients with familial amyloidotic polyneuropathy; $\mathrm{AF}_{\mathrm{TTR}}$ Met30 , amyloid fibril protein of familial amyloidotic polyneuropathy, which contains a methionine-for-valine substitution at position 30 of transthyretin; $\mathrm{CNBr}$, cyanogen bromide; FAP, familial amyloidotic polyneuropathy; FAP', type I FAP; FPLC, fast protein liquid chromatography; HPLC, high performance liquid chromatography; SAF $_{\text {TTR Met-30, serum }}$ amyloid protein of familial amyloidotic polyneuropathy that contains a methionine-for-valine substitution at position $\mathbf{3 0}$ of transthyretin; TFA, trifluoroacetic acid; TTR, transthyretin.

J. Clin. Invest.

(c) The American Society for Clinical Investigation, Inc. $0021-9738 / 86 / 05 / 1699 / 05 \quad \$ 1.00$

Volume 77, May 1986, 1699-1703 neuropathy (2). The illness is always progressive to death either from cardiac or renal failure associated with the systemic deposition of amyloid fibrils.

The diagnosis of advanced cases depends on characteristic clinical manifestations together with demonstration of amyloid deposition at biopsy. However, there has been no definite diagnositic method for this progressive disorder before symptoms appear. The mean age of onset is $34 \pm 5$ (SD) yr and patients tend to have one or two children before they develop clinical manifestations of the disease. Since this disorder is transmitted by autosomal dominant inheritance and the clinical onset is postmarital, it is important to develop an early diagnostic method to predict possible transmission of the disease. A simple and definite diagnostic test for the disease before the childbearing years is needed for appropriate genetic advice to patients and their families.

We have reported that amyloid fibril protein from Japanese patients with FAP $^{1}\left(\mathrm{AF}_{\mathrm{J}}\right)$ is a variant transthyretin ${ }^{2}$ (TTR) that contains a single amino acid substitution of a methionine for a valine at position 30 (3). This variant TTR is present in the serum of FAP ${ }^{1}$ patients along with normal TTR (4). Furthermore, we have developed a radioimmunoassay (RIA) based on a nonapeptide (positions 22-30) of the variant TTR (5).

Here we report the results of the RIA for the variant TTR, and serum levels of total TTR and total protein in 45 FAP $^{1}$ cases at different stages of illness. Their ages of onset and duration of illness are considered along with serum levels of the variant TTR. Noninheriting members of families with FAP $^{1}$, cases of primary and secondary amyloidosis, and normal individuals have been also investigated. To explore the applicability of this RIA for early detection of carriers of FAP ${ }^{1}$, we have studied 24 symptomfree children of $15 \mathrm{FAP}^{1}$ patients as well.

We believe that our diagnostic RIA is useful for early diagnosis and appropriate premarital genetic advice to FAP $^{1}$ patients and their families.

\section{Methods}

Subjects. The subjects studied here consist of 100 normal individuals aged from 2 to $70 \mathrm{yr}$ with a mean age of $30.8 \pm 10.8$ (SD) yr; 45 Japanese FAP' ${ }^{\prime}$ cases ( 22 males and 23 females) aged from 25 to $68 \mathrm{yr}$ with a mean of $41.6 \pm 11.8 ; 24$ children of FAP ${ }^{1}$ patients ( 11 males and 13 females) aged from 7 to 22 yr with a mean of $15.3 \pm 3.4 ; 26$ noninheriting members of families with FAP' aged from 31 to 69 yr with a mean of $46.9 \pm 11.4$; 4 cases of primary amyloidosis aged 43, 49,55, and $56 \mathrm{yr}$; and 6 cases of secondary amyloidosis associated with rheumatoid arthritis or polymyositis aged 36, 46, 48, 53, 59, and 59 yr. All the children of FAP ${ }^{1}$ patients were in good health up until the time when the serum studies were performed.

2. The name transthyretin has been suggested by the Nomenclature Committee of the International Union of Biochemistry and the International Union of Pure and Applied Chemistry for the protein commonly called prealbumin. 
Radioimmunoassay for the variant TTR. The nonapeptide amide (Gly-Ser-Pro-Ala-Ile-Asn-Val-Ala-Met- $\mathrm{NH}_{2}$ ) corresponding to positions 22-30 of the variant TTR was synthesized by solid-phase techniques, conducted on a $p$-methylbenzhydrylamine resin. $\mathrm{COOH}$-terminal methionine amide was changed to a mixture of homoserine and homoserine lactone by using 300-fold $\mathrm{M}$ excess of cyanogen bromide (CNBr) (Nakarai Chemicals Ltd., Kyoto, Japan) (6). COOH-terminal homoserine lactone was converted into homoserine by incubation in $0.1 \mathrm{M}$ Tris- $\mathrm{HCl}(\mathrm{pH}$ 8.0) at $40^{\circ} \mathrm{C}$ for $24 \mathrm{~h}$. The COOH-terminal homoserine form of the nonapeptide was designated as FAP nonapeptide. Purification of FAP nonapeptide was performed by reverse-phase high performance liquid chromatography (HPLC) on a $4.6 \times 250$-mm column of octadecylsilane (TSK gel ODS 120A) (Toyosoda Corp., Tokyo, Japan). A linear gradient of acetonitrile $\left(\mathrm{CH}_{3} \mathrm{CN}\right)$ from 0 to $60 \%$ in $0.1 \%$ trifluoroacetic acid (TFA) was employed for $40 \mathrm{~min}$ at a rate of $2.0 \mathrm{ml} / \mathrm{min}$. Correct synthesis was confirmed by amino acid and sequencing analyses. Tyr ${ }^{0}-$ FAP nonapeptide was synthesized in a similar manner and used for radioiodination.

FAP nonapeptide $(9.7 \mathrm{mg})$ was conjugated with bovine thyroglobulin $(9.6 \mathrm{mg})$ by the glutaraldehyde method. The resulting antigenic conjugate was emulsified with Freund's complete adjuvant and then used for immunizing New Zealand White rabbits. They were boostered every 2 wk and bled 1 wk after each injection. Tyr ${ }^{0}$-FAP nonapeptide was radioiodinated by the lactoperoxidase method (7). The ${ }^{125}$ I-labeled FAP nonapeptide was purified by reverse-phase HPLC.

RIA buffer consisted of $0.05 \mathrm{M}$ sodium phosphate (pH 7.4), $0.08 \mathrm{M}$ $\mathrm{NaCl}, 0.25 \% \mathrm{BSA}, 0.025 \mathrm{M}$ EDTA $2 \mathrm{Na}$, and $0.05 \% \mathrm{NaN}_{3}$. Samples or FAP nonapeptide standard solutions $(100 \mu \mathrm{l})$ were mixed with solutions of anti-FAP nonapeptide serum $(200 \mu \mathrm{l}$, final dilution of $1: 50,000)$ and ${ }^{125} \mathrm{I}$-labeled ligand $(200 \mu \mathrm{l}, 18,000 \mathrm{cpm})$. The mixture was incubated at $4^{\circ} \mathrm{C}$ for $40 \mathrm{~h}$. Bound and free ligands were separated by using $1 \mathrm{ml}$ of $23 \%$ polyethyleneglycol. Samples were routinely assayed in duplicate.

Immunoreactive FAP nonapeptide in the serum. $15 \mathrm{ml}$ of the serum from a biopsy proven FAP patient (64-yr-old, female) was dialyzed against $500 \mathrm{ml}$ of $30 \mathrm{mM}$ sodium phosphate buffer (pH 7.0). The dialysate was applied to an Affi-Gel Blue column $(2.3 \times 48 \mathrm{~cm}$; Bio-Rad Laboratories, Richmond, CA) preequilibrated with the above phosphate buffer. The column was washed with $480 \mathrm{ml}$ of phosphate buffer at a rate of 10 $\mathrm{ml} / \mathrm{h}$. The bound proteins were eluted with a linear gradient of sodium chloride from 0 to $1.0 \mathrm{M}$ (total volume, $500 \mathrm{ml}$ ) and then $180 \mathrm{ml}$ of 0.5 $M$ sodium thiocyanate. Each 8-ml fraction was collected. $5 \mu \mathrm{l}$ of aliquots were lyophilized, and assayed for FAP nonapeptide by RIA. $20 \mu \mathrm{l}$ of aliquots were also monitored by double immunodiffusion in two dimensions with $20 \mu \mathrm{l}$ of anti-TTR serum (Behringwerke AG, Marburg, Federal Republic of Germany) (8). The fractions exhibiting FAP nonapeptide immunoreactivity (tubes 19-23 in Fig. 2) were further submitted to fast protein liquid chromatography (FPLC) on a Mono $Q$ column $(0.5 \times 5 \mathrm{~cm}$; Pharmacia Fine Chemicals, Uppsala, Sweden) preequilibrated with $20 \mathrm{mM}$ Tris-HCl buffer ( $\mathrm{pH} 7.6$ ). The bound proteins were eluted with a linear gradient of sodium chloride (0-0.5 M) for $40 \mathrm{~min}$. The flow rate was $1.0 \mathrm{ml} / \mathrm{min}$ and the fraction size was $0.5 \mathrm{ml} / \mathrm{tube}$. All the fractions were monitored by the RIA for FAP nonapeptide and double immunodiffusion for TTR. The fractions exhibiting FAP nonapeptide immunoreactivity (tubes $56-61$ in Fig. 3 ) were purified by rechromatography on the Mono $Q$ column.

The fractions exhibiting FAP nonapeptide immunoreactivity were concentrated and desalted by the use of a Sep-Pak ODS cartridge (Waters Assoc., Milford, MA) with an elution solution of $60 \% \mathrm{CH}_{3} \mathrm{CN}$ in $0.1 \%$ TFA. The eluate was cleaved by $\mathrm{CNBr}$, incubated in $50 \mathrm{mM}$ Tris- $\mathrm{HCl}$ (pH 8.0), and digested with trypsin (treated with 1-L-tosylamido-2-phenylethyl chloromethyl ketone, TPCK) (Worthington Biochemical Corp., Freehold, $\mathrm{NJ}$ ) at $37^{\circ} \mathrm{C}$ for $2 \mathrm{~h}$ with an enzyme/substrate ratio (wt/wt) of 1:50. The reaction was stopped by the addition of $1 \mathrm{M}$ acetic acid. The tryptic digests were analyzed by reverse-phase HPLC on the column of TSK gel ODS 120A. A linear gradient of $\mathrm{CH}_{3} \mathrm{CN}(0-60 \%)$ in $0.1 \%$ TFA was employed for $40 \mathrm{~min}$. The flow rate was $2.0 \mathrm{ml} / \mathrm{min}$ and each $1-\mathrm{ml}$ fraction was collected. 5- $\mu$ l aliquots of fractions were subjected to the RIA for FAP nonapeptide. Authentic FAP nonapeptide was chromatographed on the same condition of HPLC and its elution position was compared with that of the fraction exhibiting FAP nonapeptide immunoreactivity.

Serum level of the variant TTR. $5 \mu \mathrm{l}$ of the serum of subjects were lyophilized. The serum was treated with $3 \mathrm{mg}$ of $\mathrm{CNBr}$ in $70 \%$ formic acid at room temperature for $36 \mathrm{~h}$ and then relyophilized. The resulting fragments were incubated in $100 \mu \mathrm{l}$ of $0.1 \mathrm{M}$ Tris- $\mathrm{HCl}$ to convert $\mathrm{COOH}$ terminal homoserine lactone into homoserine. The fragments were then digested with $8 \mu \mathrm{g}$ of TPCK-treated trypsin at $37^{\circ} \mathrm{C}$ for $2 \mathrm{~h}$. Thereafter, soy trypsin inhibitor was added to the buffer to stop the reaction. The serum samples were diluted with RIA buffer and were assayed for FAP nonapeptide by RIA. The amount of the variant TTR was calculated by multiplying the results of the RIA by the ratio of the molecular weight of the variant TTR $\left(M_{\mathrm{r}}=13,745\right)$ to that of FAP nonapeptide $\left(M_{\mathrm{r}}=830\right)$.

Recovery of the RIA. Serum TTR was purified from the FAP' patient by a two-step procedure using affinity chromatography on Affi-Gel Blue and anion exchange FPLC on Mono Q, and then it was submitted to amino acid analysis. The variant TTR has two methionine residues in comparison to one methionine residue in normal TTR. Therefore, the ratio of the variant TTR to normal TTR was determined by the molar quantity of a methionine residue. Since $5 \mu \mathrm{l}$ of FAP' patient's serum usually contained $500 \mathrm{ng}$ of the variant TTR, studies on the recovery of the RIA were performed by using the same amount of the variant TTR. Purified serum TTR (1,200 ng) containing $500 \mathrm{ng}$ of the variant TTR was added to $5 \mu$ l of three separate serum samples obtained from three normal individuals. Three separate normal sera prepared as above were cleaved by $\mathrm{CNBr}$ and then trypsinized. The sera were assayed for FAP nonapeptide by RIA and the amount of the variant TTR was calculated. The recovery rate was computed from the results of the RIA divided by $500 \mathrm{ng}$.

Serum level of total TTR. The serum $(5 \mu \mathrm{l})$ was applied to a single radial immunodiffusion plate for TTR (M-Partigen; Behringwerke AG, Marburg, Federal Republic of Germany). The area of a halo was measured after $48 \mathrm{~h}$ (9).

Amino acid analyses. Amino acid analysis was performed on a model 835 automated amino acid analyzer (Hitachi, Ltd., Tokyo, Japan). The peptides and proteins were hydrolyzed in $6 \mathrm{~N} \mathrm{HCl}$ containing $0.1 \%$ phenol and $0.02 \%$-mercaptoethanol at $110^{\circ} \mathrm{C}$ for $24 \mathrm{~h}$.

Statistics. Statistical analysis was performed by an independent $t$ test (Table I). $P$ value of $<0.05$ was considered significant. The results were expressed as a mean $\pm \mathrm{SD}$.

\section{Results}

RIA for FAP nonapeptide. The antiserum raised against FAP nonapeptide could bind $35-40 \%$ of ${ }^{125}$ I-labeled FAP nonapeptide at a final dilution of 50,000. A standard curve of the RIA is illustrated in Fig. 1. The sensitivity (effective dose, 10\%) of the RIA for FAP nonapeptide was $21 \mathrm{pg} /$ tube, and $238 \mathrm{pg}$ of the peptide were required to reduce binding by $50 \%$ (effective dose). Intraassay and interassay coefficients of variation were 7.5 and $6.8 \%$, respectively $(n=10)$. The serum of an FAP ${ }^{1}$ patient exhibited a dose-response curve parallel with that of FAP nonapeptide. Normal human serum, on the other hand, did not show any crossreactivity. $1 \mu \mathrm{g}$ of normal TTR, which was cleaved by

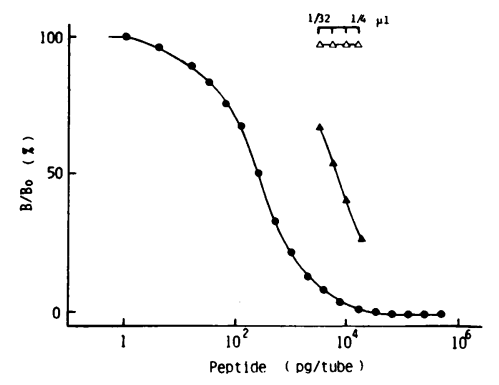

Figure 1. Dose-response curve of FAP nonapeptide (๑), dilution curves of the serum from an FAP' patient $(\Delta)$, and from a normal individual $(\Delta)$. The serum samples were diluted to the amount of $1 / 4,1 / 8$, $1 / 16$, and $1 / 32 \mu l$ of the original serum samples. 


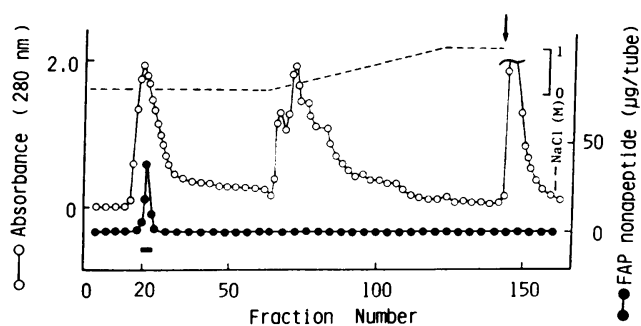

Figure 2. Separation of the serum protein from an FAP ${ }^{1}$ patient by Affi-Gel Blue chromatography. The flow rate was $10 \mathrm{ml} / \mathrm{h}$ and the fraction size was $8.0 \mathrm{ml} /$ tube. Equilibration buffer was $30 \mathrm{mM}$ sodium phosphate (pH 7.0). At tube 60, a linear $\mathrm{NaCl}$ gradient $(0-1.0 \mathrm{M}$, total volume $500 \mathrm{ml}$ ) was started. At tube 145 , indicated by an arrow, buffer was changed to $0.5 \mathrm{M}$ sodium thiocyanate. The black bar (tubes 19-23) represents fractions exhibiting TTR immunoreactivity, which was determined by double immunodiffusion in two dimensions.

$\mathrm{CNBr}$ and trypsinized, did not appreciably crossreact with the antiserum.

Identification of immunoreactivity for FAP nonapeptide. Immunoreactive FAP nonapeptide was identified by the assay of FAP nonapeptide through a two-step procedure of chromatography to isolate serum TTR. Affinity chromatography on an Affi-Gel Blue column was used as an initial step for purifying serum TTR from an FAP ${ }^{1}$ patient. TTR was not adsorbed on the dye (Cibacron Blue F3GA), but most of the serum proteins, especially albumin, bound to the dye (10). Immunoreactivity for FAP nonapeptide was observed at the same position (tubes 19-23) as that of TTR, identified by double immunodiffusion in two dimensions using anti-TTR serum, as shown in Fig. 2. Tubes 19-23 were collected and applied to anion exchange FPLC on a Mono $Q$ column. TTR was eluted later on the chromatogram and was well separated from other unretained materials on the Affi-Gel Blue resin column, since it was a strongly acidic protein (pI 4.7). A single immunoreactive peak for FAP nonapeptide was eluted at the position (tubes 56-61) corresponding to TTR as shown in Fig. 3. Therefore, it could be concluded that immunoreactive FAP nonapeptide originated from TTR. TTR purified as above was cleaved by $\mathrm{CNBr}$ and digested with trypsin. The resulting digests were separated by reverse-phase HPLC. A sharp immunoreactive peak was noted only at the position identical to authentic FAP nonapeptide as shown in Fig. 4. From the studies described above, this RIA was proved to be specific for SAF $\mathrm{TTR}_{\mathrm{TR}}$ Met-30. ${ }^{3}$ Any cross-reactive substances were not detected by the RIA.

Validation of the quantitative precision of the RIA. The RIA is standardized quantitatively for FAP nonapeptide. Before calculation of the amount of the variant TTR, the quantitative precision of the RIA was examined. Quantitative basis of the RIA was validated with a mixture of normal and the variant TTR, since normal TTR did not appreciably crossreact with the antiserum. The amounts of normal and the variant TTR were determined by amino acid analysis, based on the fact that the former had one methionine residue and the latter had two. Total serum TTR $(1,200 \mathrm{ng})$ containing $500 \mathrm{ng}$ of the variant TTR was mixed with separate sera of three normal individuals. The mixture was assayed for FAP nonapeptide by RIA, and the results

3. After the suggested nomenclature of amyloid proteins, the amyloid fibril protein of familial amyloidotic polyneuropathy of Japanese origin is designated by $\mathrm{AF}_{\mathrm{TTR}}$ Met-30 and its serum form by $\mathrm{SAF}_{\mathrm{TTR}}$ Met-30.

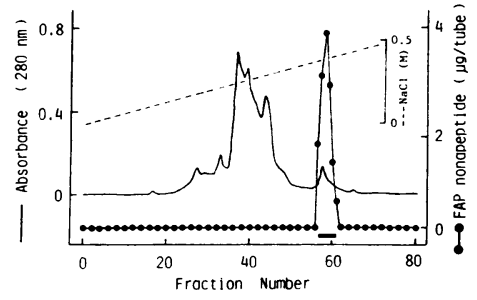

Figure 3. Anion exchange FPLC of FAP nonapeptide immunoreactive fractions obtained by Affi-Gel Blue chromatography. Tubes 1923 in Fig. 2. were collected and applied to FPLC on a Mono $Q$ column. The flow rate was $1.0 \mathrm{ml} / \mathrm{min}$ and

the fraction size was $0.5 \mathrm{ml} /$ tube. A linear gradient of $\mathrm{NaCl}(0-0.5 \mathrm{M})$ in $20 \mathrm{mM}$ Tris- $\mathrm{HCl}$ ( $\mathrm{pH} \mathrm{7.6)}$ was employed over $40 \mathrm{~min}$. The black bar (tubes 56-61) indicates fractions exhibiting TTR immunoreactivity.

were $17.6,18.1$, and $18.8 \mathrm{ng}$. These results corresponded to 296 , 305 , and $318 \mathrm{ng}$ of the variant TTR, respectively; therefore, the recovery rate was $61 \%$ as a mean. The RIA recovery was checked in every assay to validate the quantitative precision. The recovery rate was almost constant in every assay, ranging from 58 to $65 \%$.

Serum levels of the variant and total TTR. Table I summarizes serum levels of the variant and total TTR in subjects. The variant TTR was not detected in normal individuals, nor in primary and secondary amyloidosis cases. The variant TTR was not present in all the 26 noninheriting members of families with FAP $^{1}$ who were above the age of usual onset of FAP ${ }^{1}$. Serum levels of total TTR in noninheriting FAP ${ }^{1}$ ranged from 24.8 to $41.5 \mathrm{mg} / \mathrm{dl}$ with a mean of $30.0 \pm 7.7$ (SD) $\mathrm{mg} / \mathrm{dl}$, which were within normal limits.

On the other hand, all the FAP $^{1}$ patients had high serum levels of the variant TTR, ranging from 4.71 to $17.61 \mathrm{mg} / \mathrm{dl}$ with a mean of $9.18 \pm 2.69 \mathrm{mg} / \mathrm{dl}$. Their ages of onset were 23$67 \mathrm{yr}$ with a mean of $36.3 \pm 11.4 \mathrm{yr}$. Duration of illness ranged from 1 to $17 \mathrm{yr}$ with a mean of $5.5 \pm 3.6 \mathrm{yr}$. There was no significant difference in serum levels of the variant TTR between males and females, whose mean values were 10.12 and $9.82 \mathrm{mg} /$ $\mathrm{dl}$, respectively. Serum levels of total TTR in FAP ${ }^{1}$ cases ranged from 10.6 to $40.0 \mathrm{mg} / \mathrm{dl}$, which were significantly reduced as compared with normal individuals $(P<0.001)$. There were no correlations of the variant TTR level or total TTR level, with age of onset and duration of illness. The serum level of total protein in FAP $^{1}$ patients $(6.4 \pm 0.7 \mathrm{~g} / \mathrm{dl})$ was significantly lower than the control value of $7.3 \pm 0.7 \mathrm{~g} / \mathrm{dl}(P<0.002)$.

The results of the RIA for the variant TTR in 24 children of 15 FAP $^{1}$ patients are shown in Table I. Nine children had the variant TTR and their serum levels ranged from 8.32 to $14.71 \mathrm{mg} / \mathrm{dl}$. On the other hand, the variant TTR was not present in the other 15 children. There was no significant difference in serum levels of total TTR between the two groups of children.

Pedigrees of two FAP families are presented in Fig. 5, and

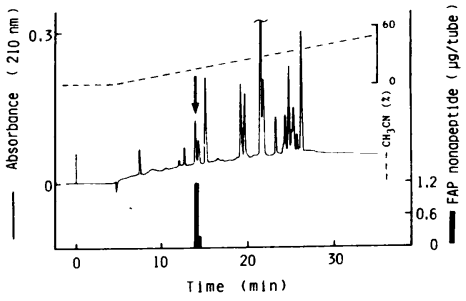

Figure 4. Tryptic peptide map for FAP' serum TTR cleaved by $\mathrm{CNBr}$. Serum TTR $(2.5 \mathrm{nmol})$ was cleaved by $\mathrm{CNBr}$, trypsinized, and then applied to reverse-phase HPLC on a TSK gel ODS $120 \mathrm{~A}$ column. The flow rate was 2.0 $\mathrm{ml} / \mathrm{min}$ and the fraction size was $1.0 \mathrm{ml} /$ tube. $\mathrm{A}$ linear $\mathrm{CH}_{3} \mathrm{CN}$ gradient $(0-60 \%)$ in $0.1 \%$ TFA was employed over $40 \mathrm{~min}$. The arrow indicates the elution position of authentic FAP nonapeptide. 
Table I. Serum Levels of the Variant and Total TTR

\begin{tabular}{lrrlll}
\hline & & \multicolumn{3}{l}{ TTR } \\
\cline { 5 - 6 } Subject & Number & Age & Variant & Total \\
\hline & & $y r$ & $m g / d l$ & $m g / d l$ \\
Normal individuals & 100 & $2-70$ & 0 & $30.5 \pm 4.5$ \\
Primary amyloidosis & 4 & $43-56$ & 0 & $35.0 \pm 6.5$ \\
Secondary amyloidosis & 6 & $36-59$ & 0 & $25.6 \pm 9.8$ \\
Noninheriting FAP & 26 & $31-69$ & 0 & $30.0 \pm 7.7$ \\
FAP $^{1}$ patients & 45 & $25-68$ & $9.18 \pm 2.69$ & $22.4 \pm 6.6$ \\
Children of FAP $^{1}$ patients & 15 & $9-19$ & 0 & $28.6 \pm 5.6$ \\
& 9 & $7-22$ & $11.90 \pm 2.33$ & $27.0 \pm 4.7$
\end{tabular}

Values are represented as a mean $\pm \mathrm{SD}$.

showed the ages of the individuals tested and serum levels of the variant TTR. Some of the siblings in the second generation were omitted to preserve anonymity. The variant TTR was detected in patients, but not in unaffected siblings. In the third generation, four of nine children had the variant TTR, whereas five children did not have it. This incidence of the variant TTR was compatible to the autosomal dominant mode of inheritance of this disorder. Thus, differentiation even within kindreds of FAP $^{1}$ was possible by studying the serum level of the variant TTR, since the latter was present only in family members inheriting this disorder.

\section{Discussion}

Recent studies have been clarifying that FAP $^{1}$ results from the deposition of structurally abnormal TTR. Costa et al. first verified in 1978 that amyloid protein in FAP ${ }^{1}$ of Portuguese origin was immunologically related to TTR (11). In 1983, Pras et al. reported that a variant TTR with a glycine-for-threonine substitution at position 49 was found in amyloid fibrils isolated from a Jewish FAP case (12). Also in 1983, another variant TTR with a methionine-for-valine substitution at position 30 was found in FAP ${ }^{1}$ of Japanese, Portuguese, and Swedish origins $(3,13$, 14). The characteristics of our studies were comparing peptide maps of amyloid protein obtained by $\mathrm{CNBr}$ and tryptic digestion with those of normal human TTR. This method was useful to determine the primary structure of amyloid protein related to TTR. After having studied $\mathrm{AF}_{\mathrm{J}}$, we applied the above peptide mapping procedure to the Jewish case. Amyloid fibril protein of Jewish FAP turned out to consist of a variant TTR with an isoleucine-for-phenylalanine substitution at position 33 and a small amount of normal TTR. In this way the original study by Pras et al. has now been revised (15). The variant TTR with a methionine-for-valine substitution is present in the serum of
FAP ${ }^{1}$ of Japanese, Portuguese, and Swedish origins $(4,16,17)$. This disorder results from the systemic deposition of amyloid fibrils that are composed of the serum variant TTR or a combination of normal TTR and its variant form. Therefore, detection of the serum variant TTR can be a new diagnostic method for this disorder. Identification of the variant TTR requires purification of serum TTR by affinity and anion exchange chromatography, and then separation of CNBr peptides by HPLC. This procedure is time consuming and requires a large amount of the serum sample becaue of a little yield of TTR. Moreover, the amount of the variant TTR cannot be determined by this method. Our RIA method is simple and quantitative for detecting the variant TTR, which is based on the finding that the variant TTR has an extra methionine at position 30 .

Serum TTR from Japanese FAP ${ }^{1}$ patients contains normal and the variant TTR. The structural difference between two TTR is only one amino acid replacement. Thus, it is difficult to differentiate the two immunologically with the antiserum against the whole variant. Since the variant TTR has a methionine-forvaline substitution, the protein is cleaved by $\mathrm{CNBr}$ at position 30. $\mathrm{CNBr}$ cleavage followed by tryptic digestion produces a nonapeptide (positions 22-30) from the variant as indicated in Fig. 6. On the other hand, normal TTR does not give the nonapeptide by this treatment. Once the RIA specific for the nonapeptide has been developed, the variant TTR can be differentiated from normal TTR. Homoserine lactone generated by $\mathrm{CNBr}$ cleavage has been converted to homoserine in order to establish a highly sensitive RIA. The nonapeptide with homoserine at the $\mathrm{COOH}$ terminus is designated as FAP nonapeptide.

The variant TTR is present in all the $45 \mathrm{FAP}^{1}$ patients studied in our series, but is not present in normal individuals, other types of amyloidosis, nor in noninheriting members of families with FAP ${ }^{1}$. Further studies on offsprings of patients revealed that the variant TTR is already present in half of their children, but is not present in the other half, as shown in Fig. 5. The variant TTR exists long before the clinical onset of the disease, which can be utilized to make early diagnosis of this illness even before the clinical onset of FAP'.

The serum level of TTR is closely related to the nutritional status of the individual, since TTR has a rapid turnover rate, with a biological half-life of $2 \mathrm{~d}$ (18). Reduced serum levels of total TTR and total protein in FAP ${ }^{1}$ patients are probably due to poor nutritional state caused by alternating diarrhea and constipation, severe epigastralgia, and vomiting. The wide variety of serum levels of the variant TTR $(4.71-17.61 \mathrm{mg} / \mathrm{dl})$ and total TTR $(10.6-40.0 \mathrm{mg} / \mathrm{dl})$ in patients at different stages of illness are partly related to their nutritional status.

Serum TTR in FAP ${ }^{1}$ patients is a mixture of normal and the variant $T T R$ in an approximately equal ratio. This ratio suggests that two TTR are the products of a co-dominant expression of two allelic genes in the heterogeneous state. It is

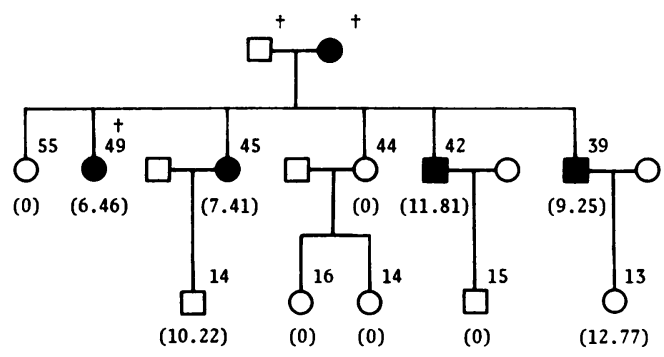

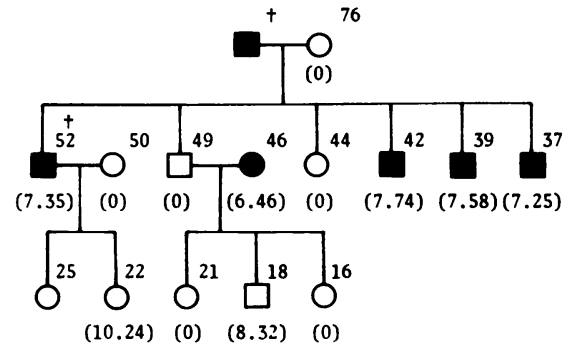

Figure 5. Samples of sibship and analysis by the RIA. Some of the siblings in the second generation are omitted to protect anonymity. The age is presented at the right upper side of the symbol. The serum level of the variant TTR is shown in parentheses. $\square$, affected; $\square$, unaffected; and $\dagger$, deceased. 


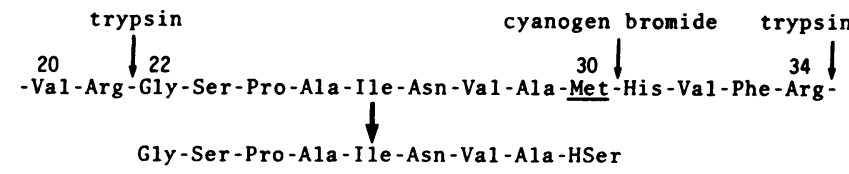

( FAP nonapeptide)

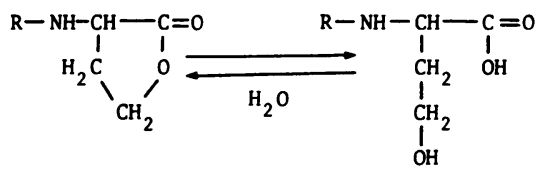

(A)

( B )

Figure 6. Principle of the RIA based on FAP nonapeptide. Partial amino acid sequence near position 30 of the variant TTR is shown. Small arrows indicate bonds that are cleaved by $\mathrm{CNBr}$ and trypsin. A methionine residue is changed to a mixture of homoserine lactone $(A)$ and homoserine $(B)$ by $\mathrm{CNBr}$ cleavage. Homoserine lactone is converted into homoserine (HSer) to establish a highly sensitive RIA. The nonapeptide with homoserine at the $\mathrm{COOH}$-terminus is designated as FAP nonapeptide.

also possible that identical paternal and maternal TTR genes are expressed simultaneously in normal individuals. cDNA for human TTR has been recently cloned and its nucleotide sequence has been determined (19). One allele of TTR gene in FAP ${ }^{1}$ patients has undergone mutation resulting in guanine-toadenine transition in the $5^{\prime}$ terminal position of the valine codon at position 30. This transition is responsible for the substitution of methionine for valine. FAP ${ }^{1}$ is considered to be transmitted by this abberant TTR gene.

Measurement of the serum variant TTR can serve as a new, noninvasive diagnostic method for the disease. It is also helpful as a wide screening test for the population of districts inhabited by conglomerations of diseased families. We can also predict whether or not a member of an FAP' family who is younger than the age of usual onset is likely to develop the disease in the future. Furthermore, members of families with FAP ${ }^{1}$ can do better family planning, being assured whether or not they can have children without worrying about transmission of the disorder. This RIA is applicable for the detection of the variant TTR in the tissue samples as well as in the serum. It would be a quick method for identifying amyloid fibril protein of the various types of FAP in the world, for which a method has not yet been determined. SAF TTR Met-30 is present in FAP $^{1}$ patients from Portugal, Sweden, Japan, and other countries, which indicates that this RIA can be widely applied to FAP ${ }^{1}$ throughout the world for early diagnosis and genetic counseling before the childbearing age.

\section{Acknowledgments}

We thank Dr. Y. Kuroiwa and Dr. I. Goto at Kyushu University, Dr. S. Araki at Kumamoto University, Dr. S. Kito at Hiroshima University, Dr. T. Suzuki at Osaka University, Dr. S. Ikeda at Shinshu University, and Drs. K. Ichikawa and E. Mizuta at Hyogo Prefectural Hospital for their cooperation in obtaining blood samples from FAP ${ }^{1}$ patients and their families.

This work was supported in part by a grant-in-aid from the Ministry of Health and Welfare Primary Amyloidosis Research Committee of Japan.

\section{References}

1. Glenner, G. G., T. F. Ignaczak, and D. L. Page. 1978. The inherited systemic amyloidoses and localized amyloid deposits. In The Metabolic Basis of Inherited Disease. J. B. Stanbury, J. B. Wyngaarden, and D. S. Fredrickson, editors. McGraw-Hill, New York. 1308-1339.

2. Araki, S., T. Kurihara, S. Tawara, and T. Kuribayashi. 1980. Familial amyloidotic polyneuropathy in Japanese. Clinical, pathophysiological, biochemical, and therapeutic studies. In Amyloid and Amyloidosis. G. G. Glenner, P. P. Costa, and A. F. Freitas, editors. Excerpt Medica, Amsterdam. 67-77.

3. Tawara, S., M. Nakazato, K. Kangawa, H. Matsuo, and S. Araki. 1983. Identification of amyloid prealbumin variant in familial amyloidotic polyneuropathy (Japanese type). Biochem. Biophys. Res. Commun. 116:880-888.

4. Nakazato, M., K. Kangawa, N. Minamino, S. Tawara, H. Matsuo, and $S$. Araki. 1984. Identification of a prealbumin variant in the serum of a Japanese patient with familial amyloidotic polyneuropathy. Biochem. Biophys. Res. Commun. 122:712-718.

5. Nakazato, M., K. Kangawa, N. Minamino, S. Tawara, H. Matsuo, and S. Araki. 1984. Radioimmunoassay for detecting abnormal prealbumin in the serum for diagnosis of familial amyloidotic polyneuropathy (Japanese type). Biochem. Biophys. Res. Commun. 122:719-725.

6. Gross, E. 1967. The cyanogen bromide reaction. Methods Enzymol. 11:238-255.

7. Miyachi, Y., J. L. Vaitukaitis, E. Nieschlag, and M. B. Lipset. 1972. Enzymatic radioiodination of gonadotropins. J. Clin. Endocrinol. Metab. 34:23-28.

8. Ouchterlony, O. 1958. Diffusion-in-gel methods for immunological analysis. In Progress in Allergy. P. Kallos, editor. Karger, Basel and New York. 1-78.

9. Mancini, G., A. O. Carbonara, and J. F. Heremans. 1965. Immunochemical quantitation of antigens by single radial immunodiffusion. Immunochemistry. 2:235-254.

10. Gianazza, E., and P. Arnaud. 1982. A general method for fractionation of plasma proteins. Biochem. J. 201:129-136.

11. Costa, P. P., A. S. Figueira, and F. R. Bravo. 1978. Amyloid fibril protein related to prealbumin in familial amyloidotic polyneuropathy. Proc. Natl. Acad. Sci. USA. 75:4499-4503.

12. Pras, M., F. Prelli, E. C. Franklin, and B. Frangione. 1983. Primary structure of an amyloid prealbumin variant in familial polyneuropathy of Jewish origin. Proc. Natl. Acad. Sci. USA. 80:539-542.

13. Saraiva, M. J. M., P. P. Costa, S. Birken, and D. S. Goodman. 1983. Presence of an abnormal transthyretin (prealbumin) in Portuguese patients with familial amyloidotic polyneuropathy. Trans. Assoc. Am. Physians. 96:261-270.

14. Dwulet, F. E., and M. D. Benson. 1983. Polymorphism of human plasma thyroxine prealbumin. Biochem. Biophys. Res. Commun. 114: 657-662.

15. Nakazato, M., K. Kangawa, N. Minamino, S. Tawara, H. Matsuo, and S. Araki. 1984. Revised analysis of amino acid replacement in a prealbumin variant (SKO-III) associated with familial amyloidotic polyneuropathy of Jewish origin. Biochem. Biophys. Res. Commun. 123: 921-928.

16. Saraiva, M. J. M., S. Birken, P. P. Costa, and D. S. Goodman. 1984. Amyloid fibril protein in familial amyloidotic polyneuropathy, Portuguese type. J. Clin. Invest. 74:104-119.

17. Dwulet, F. E., and M. D. Benson. 1984. Primary structure of an amyloid prealbumin and its plasma precursor in a heredofamilial polyneuropathy of Swedish origin. Proc. Natl. Acad. Sci. USA. 81:694-698.

18. Socolow, E. L., K. A. Woeber, R. H. Purdy, M. R. Holloway, and S. H. Ingbar. 1965. Preparation of $\mathrm{I}^{131}$-labeled human serum prealbumin and its metabolism in normal and sick patients. J. Clin. Invest. 44:1600-1609.

19. Sasaki, H., Y. Sakaki, H. Matsuo, I. Goto, Y. Kuroiwa, I. Sahashi, A. Takahashi, T. Shinoda, T. Isobe, and Y. Takagi. 1984. Diagnosis of familial amyloidotic polyneuropathy by recombinant DNA techniques. Biochem. Biophys. Res. Commun. 125:636-642. 